\title{
Chemogenetic Activation of an Extinction Neural Circuit Reduces Cue-Induced Reinstatement of Cocaine Seeking
}

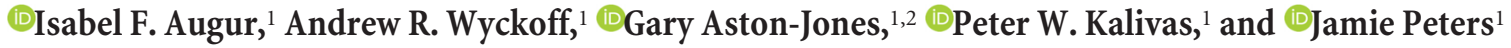 \\ ${ }^{1}$ Department of Neuroscience, Medical University of South Carolina, Charleston, South Carolina 29425, and ${ }^{2}$ Rutgers University and Rutgers Biomedical \\ and Health Sciences, Piscataway, New Jersey 08854
}

The ventromedial prefrontal cortex (vmPFC) has been shown to negatively regulate cocaine-seeking behavior, but the precise conditions by which vmPFC activity can be exploited to reduce cocaine relapse are currently unknown. We used viral-mediated gene transfer of designer receptors (DREADDs) to activate vmPFC neurons and examine the consequences on cocaine seeking in a rat self-administration model of relapse. Activation of vmPFC neurons with the Gq-DREADD reduced reinstatement of cocaine seeking elicited by cocaineassociated cues, but not by cocaine itself. We used a retro-DREADD approach to confine the Gq-DREADD to vmPFC neurons that project to the medial nucleus accumbens shell, confirming that these neurons are responsible for the decreased cue-induced reinstatement of cocaine seeking. The effects of vmPFC activation on cue-induced reinstatement depended on prior extinction training, consistent with the reported role of this structure in extinction memory. These data help define the conditions under which chemogenetic activation of extinction neural circuits can be exploited to reduce relapse triggered by reminder cues.

Key words: DREADD; extinction; infralimbic; memory; nucleus accumbens shell

\section{Significance Statement}

The ventromedial prefrontal cortex (vmPFC) projection to the nucleus accumbens shell is important for extinction of cocaine seeking, but its anatomical proximity to the relapse-promoting projection from the dorsomedial prefrontal cortex to the nucleus accumbens core makes it difficult to selectively enhance neuronal activity in one pathway or the other using traditional pharmacotherapy (e.g., systemically administered drugs). Viral-mediated gene delivery of an activating Gq-DREADD to vmPFC and/or vmPFC projections to the nucleus accumbens shell allows the chemogenetic exploitation of this extinction neural circuit to reduce cocaine seeking and was particularly effective against relapse triggered by cocaine reminder cues.

\section{Introduction}

Cocaine addiction is characterized by episodes of recurrent relapse, which is often triggered by environmental reminder cues associated with the drug experience (Pickens et al., 2011; Sinha, 2013). Animal models have implicated the medial prefrontal cortex (mPFC) as a critical structure for regulating relapse (Kalivas,

Received March 6, 2016; revised Aug. 11, 2016; accepted Aug. 13, 2016.

Author contributions: G.A.-J., P.W.K., and J.P. designed research; I.F.A., A.R.W., and J.P. performed research;

I.F.A., A.R.W., and J.P. analyzed data; I.F.A. and J.P. wrote the paper.

This work was supported by National Institute on Drug Abuse/National Institutes of Health Grants K01 DA038235 and P50 Pilot Grant DA015369 to J.P., R01 DA006214 to G.A.J., and R01 DA012513 to P.W.K., and the Brain and Behavior Research Foundation National Alliance for Research on Schizophrenia and Depression Grant to J.P. CNO and cocaine hydrochloride were generous gifts from the National Institute on Drug Abuse Drug Supply Program. CAV2Cre was a generous gift from Dr. Eric Kremer at the Institut de Génétique Moléculaire de Montpellier, France. We thank Dr. Carmela Reichel for providing behavioral chambers and other resources used to conduct these experiments, and Mr. Jasper Heinsbroek for support in generating figures.

The authors declare no competing financial interests.

Correspondence should be addressed to Dr. Jamie Peters, Department of Neuroscience, Medical University of South Carolina, 173 Ashley Avenue, Suite 403 BSB, Charleston, SC 29425. E-mail: petersjl.upr@gmail.com.

DOI:10.1523/JNEUROSCI.0773-16.2016

Copyright $\odot 2016$ the authors $\quad 0270-6474 / 16 / 3610174-07 \$ 15.00 / 0$
2008). A dorsal-ventral distinction exists within the mPFC wherein dorsomedial prefrontal cortex (dmPFC) regions promote relapse and ventromedial prefrontal cortex (vmPFC) regions promote extinction-like reductions in cocaine seeking (Peters et al., 2009; Moorman et al., 2015). These bidirectional effects on cocaine-seeking behavior are mediated, at least in part, via anatomically distinct projections to the nucleus accumbens, which integrates information from limbic structures to regulate motivated behaviors (Sesack et al., 1989; Berendse et al., 1992). Thus, treatments that alter activity in these neural pathways may disrupt the propensity to relapse.

Most of the evidence supporting this dichotomy of function within $\mathrm{mPFC}$ stems from deactivation studies, wherein $\mathrm{mPFC}$ activity is reduced or eliminated, for example, through local pharmacology or focal lesions (Weissenborn et al., 1997; McFarland and Kalivas, 2001; McLaughlin and See, 2003; Peters et al., 2008). In these studies, deactivation of dmPFC reduces relapse triggered by both conditioned stimuli (CS, e.g., cocaineassociated cues) and unconditioned stimuli (US, e.g., cocaine) (McFarland and Kalivas, 2001; McLaughlin and See, 2003; Peters 
et al., 2008). By contrast, deactivating vmPFC under the same circumstances elicits no effect (McFarland and Kalivas, 2001; Capriles et al., 2003). Rather, deactivation of vmPFC is sufficient to induce relapse to cocaine seeking (for heroin seeking, see Peters et al., 2008; Bossert et al., 2011, 2012; for drug differences, see review by Peters et al., 2013). Some evidence suggests that these roles are established over the course of protracted withdrawal from cocaine, in part through neuroadaptations at mPFC synapses onto nucleus accumbens neurons (Ma et al., 2014). Another factor that may be critical in establishing the vmPFC as an inhibitor of cocaine seeking is extinction training, as at least one study suggests that the vmPFC may drive the incubation of cocaine seeking after abstinence (Koya et al., 2009).

Extinction refers to a process whereby CS are learned to no longer be associated with the US. This may partly involve degradation of the original associative memory but also involves new learning about the changing contingency between the CS and the US (Bouton, 2002, 2006; Dunsmoor et al., 2015). The vmPFC in particular has been noted for its involvement in extinction memory, not just for cocaine-associated memories, but also for conditioned fear (Peters et al., 2009). Optogenetic activation of vmPFC neurons during extinction training facilitates subsequent extinction memory retrieval for both cocaine and fear memories (Van den Oever et al., 2013; Do-Monte et al., 2015). Local pharmacological activation of vmPFC (with AMPA receptor agonists) also enhances extinction memory consolidation and reduces reinstatement (i.e., relapse) of cocaine seeking (Peters et al., 2008; LaLumiere et al., 2010, 2012). Extinction training has had limited clinical success in substance abusers (Nic Dhonnchadha and Kantak, 2011), but when successful, has been associated with memory mechanisms in vmPFC (Xue et al., 2012). Treatments that enhance vmPFC activity may thus be useful pharmacological adjuncts to behavioral therapy.

The present studies were designed to examine the therapeutic potential of vmPFC-designer receptors exclusively activated by designer drugs (DREADDs) on cocaine seeking in an animal model of cocaine self-administration and relapse. We focused on the Gq-DREADD (hM3Dq) as a means of activating vmPFC neurons to promote extinction and reduce reinstatement. The GqDREADD has been shown to depolarize neurons through $\mathrm{Gq}$ signaling and subsequent release of calcium from internal stores (Armbruster et al., 2007; Alexander et al., 2009). This in turn promotes neuronal burst firing, and vmPFC-neuron bursting is associated with enhanced extinction memory retrieval (BurgosRobles et al., 2007). Thus, we hypothesized that the vmPFC-GqDREADD would promote extinction memory retrieval and reduce cocaine seeking.

\section{Materials and Methods}

Subjects. Male Sprague Dawley rats (Charles River Laboratories; \#Crl: CD(SD), RRID:RGD_734476) weighing 250-300 g on arrival were individually housed in a temperature and humidity controlled environment with a $12 \mathrm{~h}$ light/dark cycle (6:00 A.M. lights off). Experiments were conducted during the rats' dark cycle. Rats were mildly food-restricted to $20-25 \mathrm{~g}$ of food per day to promote behavioral performance. Water was available ad libitum in the home cage.

Drugs. Cocaine hydrochloride and clozapine- $N$-oxide $(\mathrm{CNO})$ were obtained through the National Institute on Drug Abuse Drug Supply Program. Cocaine was dissolved in saline, and $\mathrm{CNO}$ was dissolved in 5\% DMSO + 95\% saline. CNO was administered at a dose of $10 \mathrm{mg} / \mathrm{ml} / \mathrm{kg}$ (i.p.) based on reports indicating that this may be a minimal effective dose in some systems (Li et al., 2013; Chiarlone et al., 2014; Mahler et al., 2014). A pretreatment interval of $1 \mathrm{~h}$ was used based on the prolonged pharmacokinetics of $\mathrm{CNO}$-induced behavioral and neurophysiological effects (Alexander et al., 2009).

Surgery. Surgery was performed under ketamine/xylazine (100/6.7 $\mathrm{mg} / \mathrm{kg}$ ) anesthesia, and ketorolac $(15 \mathrm{mg} / \mathrm{kg}$ ) was administered for analgesia. Rats were implanted with intravenous catheters and bilateral intracranial cannula directed at the vmPFC or the vmPFC and nucleus accumbens shell (NAshell). Cannulae were used to guide subsequent microinjections of DREADD vectors into these targets. Stereotaxic coordinates for the vmPFC were $2.9 \mathrm{~mm}$ anterior-posterior, $\pm 0.6 \mathrm{~mm}$ mediolateral, and $-2.5 \mathrm{~mm}$ dorsoventral. Stereotaxic coordinates for the NAshell were $1.4 \mathrm{~mm}$ anterior-posterior, $\pm 0.8 \mathrm{~mm}$ mediolateral, and $-6.0 \mathrm{~mm}$ dorsoventral. Injectors extended $3 \mathrm{~mm}$ beyond cannula for vmPFC and $2 \mathrm{~mm}$ for NAshell. Rats recovered for 5-10 d before initiating behavioral procedures.

Cocaine self-administration. All rats were trained to self-administer cocaine by pressing the active lever, which delivered a cocaine infusion $(0.31 \mathrm{mg} / 86 \mu \mathrm{l} / 5 \mathrm{~s})$ on an FR1-20 s schedule of reinforcement $(20 \mathrm{~s}$ timeout). A cue light ( $5 \mathrm{~s})$ above the active lever and tone $(4 \mathrm{kHz}, 78 \mathrm{~dB}$, $5 \mathrm{~s})$ was paired with each cocaine infusion. This cue was used as a reminder to trigger reinstatement at a later stage. Pressing on the inactive lever never produced any consequences. Self-administration sessions lasted $2 \mathrm{~h}$ and were conducted 5-6 d/week for a total of 12-14 sessions. At the start of the study, we conducted a single food-training session before cocaine training to facilitate acquisition and maintain consistency with our previous work (Peters et al., 2008). We also found that withholding the inactive lever for the first two or three sessions of self-administration similarly accelerated acquisition; thus, we adopted the latter procedure for the remainder of the study.

Virus microinjection. The Gq-DREADD (AAV2-hSyn-HA-hM3D(Gq)IRES mCitrine, Bryan Roth, University of North Carolina, Chapel Hill, NC) was microinjected into vmPFC $\left(5.1-6.1 \times 10^{12}\right.$ viral genomes, vg $/ \mathrm{ml} ; 0.5$ $\mu \mathrm{l} / \mathrm{side}$ at $0.1 \mu \mathrm{l} / \mathrm{min}) 2 \mathrm{~d}$ after the last cocaine self-administration session. We allowed $26 \mathrm{~d}$ for Gq-DREADD expression to accumulate before $\mathrm{CNO}$ testing began. For the retro-DREADD experiment, CAV2-Cre (Eric Kremer, Montpellier Vector Platform) was microinjected into NAshell (1-1.2 $\times 10^{12}$ $\mathrm{vg} / \mathrm{ml} ; 0.75 \mu \mathrm{l} / \mathrm{side}$ at $0.15 \mu \mathrm{l} / \mathrm{min}$ ) $7 \mathrm{~d}$ before $\mathrm{vmPFC}$ microinjection of the Cre-dependent Gq-DREADD (AAV2-hSyn-DIO-hM3D(Gq)-mCherry, Bryan Roth, University of North Carolina, Chapel Hill, NC; 5.1-6.1 $\times 10^{12}$ $\mathrm{vg} / \mathrm{ml} ; 0.5 \mu \mathrm{l} /$ side at $0.1 \mu \mathrm{l} / \mathrm{min})$. As a control, some rats received the Credependent channelrhodopsin (ChR2) instead of hM3Dq into vmPFC under similar parameters (AAV2-EF1a-DIO-hChR2-eYFP, Karl Deisseroth, University of North Carolina, Chapel Hill, NC; $6.2 \times 10^{12} \mathrm{vg} / \mathrm{ml} ; 0.5 \mu \mathrm{l} / \mathrm{side}$ at $0.1 \mu \mathrm{l} / \mathrm{min}$ ). All viral microinfusions were administered under brief isoflurane anesthesia through chronic indwelling cannula. This entailed $\sim 5 \mathrm{~min}$ of anesthesia induction in a vapor chamber, followed by $5-10$ min of microinfusion and an additional $10 \mathrm{~min}$ to allow the injected virus to diffuse before removal of the microinjectors.

Abstinence versus extinction. During abstinence, rats remained in the home cage, and no behavior sessions or cocaine exposure occurred. Rats were weighed and handled every few days. Extinction training, wherein responding on both levers was without consequence, was conducted over 10 sessions each weekday in $1 \mathrm{~h}$ sessions.

Cue-induced reinstatement testing. After extinction or abstinence, rats were pretreated with vehicle or $\mathrm{CNO}$ and placed in behavioral chambers for a cue-induced reinstatement test $(28 \mathrm{~d}$ after the last cocaine selfadministration session). A single noncontingent presentation of the light-tone cue (paired with cocaine during self-administration) was delivered at the start of the session as a reminder to trigger reinstatement. During this $1 \mathrm{~h}$ test session, responding on the active lever resulted in the light-tone cue (FR1-20 s), but not cocaine.

Cocaine-primed reinstatement test. Rats continued running on the same program used for cue-induced reinstatement in daily $1 \mathrm{~h}$ sessions until they extinguished the cocaine cues $(<30$ active lever presses over 2 consecutive sessions). On the test day, rats were pretreated with vehicle or $\mathrm{CNO}$ and administered a noncontingent injection of cocaine $(10 \mathrm{mg} /$ $\mathrm{ml} / \mathrm{kg}$, i.p.) immediately before placement in the test chamber. The session parameters were otherwise the same as the cue-induced reinstatement test. Testing was conducted in a within-subjects fashion over 2 tests 
with at least $2 \mathrm{~d}$ of intermittent cue extinction sessions to reestablish a baseline.

Immunohistochemistry and Fos quantification. At the end of the experiment, rats were transcardially perfused with $10 \%$ buffered formalin, and brains were removed for subsequent immunohistochemistry on free-floating $(40 \mu \mathrm{m})$ sections. Tissue was treated with peroxidase, then blocked with $2 \%$ normal donkey serum in PBS. Sections were incubated overnight at $4^{\circ} \mathrm{C}$ in primary antibody: mouse antihemagglutinin (HA) (1:1000; Covance \#MMS101-P, RRID:AB_2314672), rabbit antidsRed (1:1000; Clontech \#632496, RRID: AB_10013483), chicken anti-mCherry (1: 3000; LifeSpan Biosciences \#LS-C204825), chicken anti-YFP (1:2000; Abcam \#ab13970 RRID:AB_300798), or rabbit anti-Fos (1:1000; Millipore \#ABE457). Secondary antibodies were biotin-SP conjugated donkey anti-mouse IgG, anti-rabbit IgG, or anti-chicken IgY (all 1:500; Jackson ImmunoResearch Laboratories). The signal was amplified with an avidin-biotin complex (1:500), then reacted with diaminobenzidine (in 5\% nickel). Tissue was mounted onto slides, dehydrated, coverslipped, and examined under a microscope to visualize Gq-DREADD, ChR2, or Fos expression. Subjects were eliminated from the final dataset if no DREADD expression was visible in vmPFC, or if there was substantial spread into dmPFC, as specified in Results. For Fos quantification, vmPFC sections were imaged under a $10 \times$ objective on an Olympus BX61 microscope using a DVC camera and Stereo Investigator software (MBF Bioscience). Fos-positive $\left(\mathrm{Fos}^{+}\right)$nuclei were counted in 3 or 4 sections bilaterally from vmPFC of each animal. Counting was automated using a set threshold for detection in ImageJ software (National Institutes of Health).

Statistical analysis. Data were analyzed using $t$ tests, paired or unpaired as appropriate. A Welch's correction was used if the variances in the two groups were unequal. Statistical significance was set at an $\alpha$ level of 0.05 . Subjects were eliminated from the final dataset if their data deviated from the average by $>2$ SDs, as specified below in Results.

\section{Results}

\section{Chemogenetic activation of vmPFC reduces cue-induced reinstatement of cocaine seeking after extinction}

Rats $(n=24)$ underwent cocaine self-administration and received infusions of AAV-hSyn-hM3Dq into vmPFC $2 \mathrm{~d}$ after their last session. Extinction training began after $14 \mathrm{~d}$ of abstinence, and rats gradually reduced responding on the active lever over 10 daily sessions. The next day, they were tested for cueinduced reinstatement after pretreatment with vehicle $(n=11)$ or $\mathrm{CNO}(n=9 ; 10 \mathrm{mg} / \mathrm{kg}$, i.p.; $1 \mathrm{~h}$ prior). CNO significantly reduced cue-induced reinstatement of active lever responding $\left(t_{(18)}=2.168, p=0.044\right)$ (Fig. 1A). No effects were observed on the inactive lever $\left(t_{(18)}=0.812, p=0.427\right.$, vehicle $=8 \pm 2$, $\mathrm{CNO}=11 \pm 3)$. One rat in the $\mathrm{CNO}$ group was a statistical outlier and was eliminated. Importantly, treatment groups did not differ in their average lever pressing at the end of selfadministration (Active lever: $t_{(18)}=0.333, p=0.743$, vehicle $=$ $42 \pm 9, \mathrm{CNO}=38 \pm 8$; Inactive lever: $t_{(18)}=0.917, p=0.371$, vehicle $=2 \pm 2, \mathrm{CNO}=1 \pm 0$ ) or their total cocaine intake over the course of self-administration $\left(t_{(18)}=0.360, p=0.723\right.$, vehicle $=328 \pm 49 \mathrm{mg} / \mathrm{kg}, \mathrm{CNO}=301 \pm 57 \mathrm{mg} / \mathrm{kg}$ ).

After extinguishing responding for the cocaine-associated cues, a subset of these rats $(n=16)$ was tested for cocaine-primed reinstatement after pretreatment with vehicle or $\mathrm{CNO}$. Each rat received one test with vehicle, and one with $\mathrm{CNO}$, in a randomized order. CNO did not alter cocaine-primed reinstatement (Ac-
B
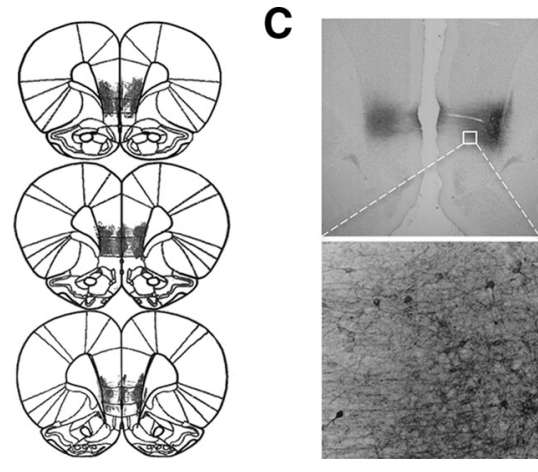

Figure 1. Activation of vmPFC with a Gq-DREADD reduces cue-induced cocaine seeking after extinction. $\boldsymbol{A}$, Active (shaded bars) located primarily within infralimbic cortex.

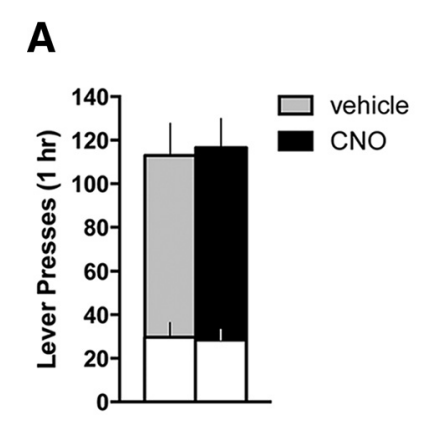

Figure 2. Activation of vmPFC with a Gq-DREADD does not alter cocaine seeking in the presence of cocaine cues after abstinence. $\boldsymbol{A}$, Neither active (shaded bars) nor inactive (white bars) lever presses differed for CNO versus vehicle-treated animals during the cocaine-seeking test $(p>0.8)$. $\boldsymbol{B}$, Histological verification of the extent of DREADD expression indicated robust and restricted expression in vmPFC.

tive lever: $t_{(12)}=0.624, p=0.545$, Inactive lever: $t_{(12)}=1.000$, $p=0.337$ ) (Fig. 1A). Histological analysis revealed expression of the hM3Dq DREADD was centralized in the infralimbic cortex for most animals (Fig. $1 B$ ). Three rats were eliminated: two were lacking DREADD expression, and one had substantial expression in dmPFC. In sum, DREADD activation of vmPFC specifically reduced cocaine seeking triggered by cocaine cues.

We next asked whether extinction training was required for vmPFC activation to effectively reduce cocaine seeking. Hence, we repeated the previous experiment but eliminated the extinction phase. Instead, animals $(n=16)$ remained in their home cage during the equivalent time frame. Chemogenetic activation of vmPFC did not reduce cocaine seeking in these animals (Active lever: $t_{(12)}=0.180, p=0.860$; Inactive lever: $t_{(12)}=0.156, p=$ 0.879 ) (Fig. $2 A$ ), even though expression of the Gq-DREADD in vmPFC (Fig. $2 B$ ) was similar to the previous cohort. One animal was eliminated due to a lack of DREADD expression, as well as one statistical outlier in the vehicle group. Treatment groups did not differ in their average lever pressing at the end of selfadministration (Active lever: $t_{(12)}=0.564, p=0.583$, vehicle $=$ $37 \pm 5, \mathrm{CNO}=33 \pm 4$; Inactive lever: $t_{(12)}=0.745, p=0.471$, vehicle $=1 \pm 1, \mathrm{CNO}=2 \pm 1$ ) or their total cocaine intake over the course of self-administration $\left(t_{(12)}=0.389, p=0.704\right.$, vehicle $=260 \pm 16 \mathrm{mg} / \mathrm{kg}, \mathrm{CNO}=249 \pm 23 \mathrm{mg} / \mathrm{kg})$. The relapsereducing effects of vmPFC activation thus may depend on 
A
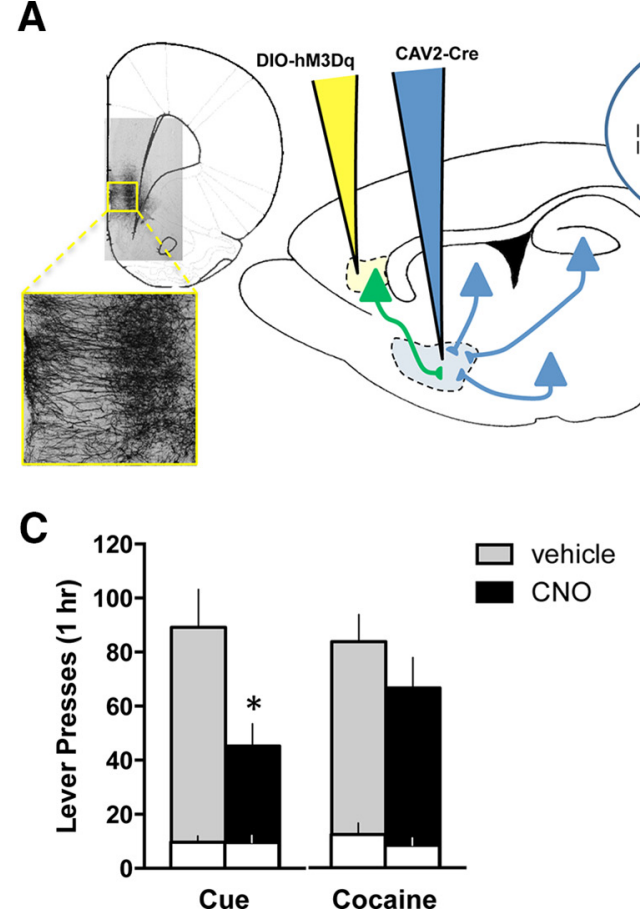
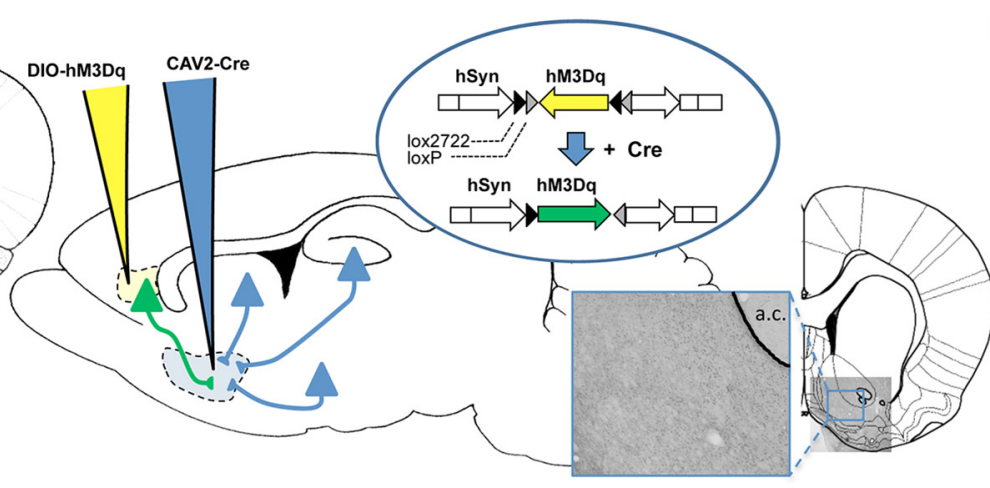

B

D

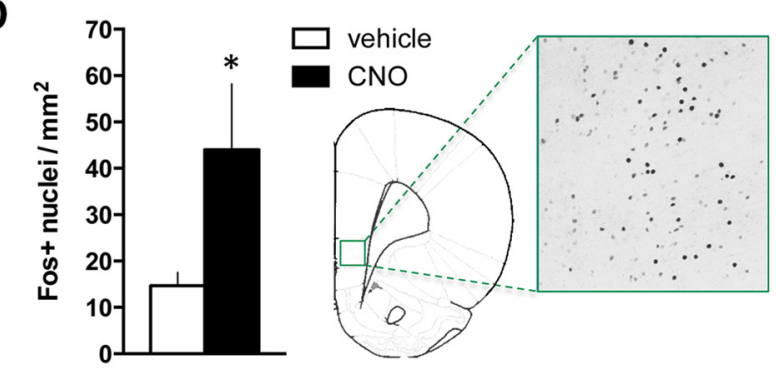

Figure 3. Activation of the vmPFC projection to the NAshell using a retro-DREADD approach reduces cue-induced reinstatement of cocaine seeking. $A$, The retro-DREADD approach used to target the vmPFC projection to the NAshell is depicted. CAV2-Cre was infused into the NAshell (blue pipet), and the AAV-DI0-hM3Dq(Gq) DREADD (yellow pipet) was infused into vmPFC. Cre-lox recombination thus restricts expression of the hM3Dq to vmPFC neurons projecting to the NAshell (green). Representative photomicrographs demonstrating expression of the Gq-DREADD (mCherry tag) in vmPFC cell bodies and dendrites (left) and NAshell fibers and terminals (right), relative to the anterior commissure (a.c.). $\boldsymbol{B}$, Histological verification of the extent of DREADD expression indicated robust and restricted expression in vmPFC. C, Active (shaded bars) and inactive (white bars) lever presses are shown for the cue-induced and cocaine-primed reinstatement tests. ${ }^{*} p<$ 0.05 , comparing vehicle with CNO for active lever. $D$, The number of Fos ${ }^{+}$nuclei in vmPFC (per mm ${ }^{2}$ tissue) induced by a final CNO injection is shown, along with a representative image. ${ }^{*} p<0.05$, comparing vehicle with CNO.

extinction-induced plasticity, either within vmPFC or in downstream structures (e.g., the NAshell).

\section{Selective activation of vmPFC projections to the NAshell reduces cue-induced reinstatement of cocaine seeking} As previous data implicated the NAshell as an important vmPFC efferent target responsible for extinction expression, we sought to determine whether NAshell-projecting vmPFC neurons mediate the effects of the Gq-DREADD on cue-induced cocaine seeking. We chose a retro-DREADD approach to selectively express the Gq-DREADD in these neurons (Fig. 3A) (Boender et al., 2014; Kerstetter et al., 2016; Marchant et al., 2016). The retrogradetraveling CAV2-Cre virus was infused into NAshell, and a Cre-dependent AAV-DIO-hM3Dq into vmPFC. Experimental parameters were otherwise similar to our initial experiment with extinction-trained animals for this cohort $(n=19)$. One rat failed to acquire cocaine self-administration and was eliminated before testing. One vehicle rat was eliminated as a statistical outlier on the test. CNO pretreatment before cue-induced reinstatement testing significantly reduced cocaine seeking on the active $\left(t_{(13)}=\right.$ $2.902, p=0.012)$, but not inactive $\left(t_{(13)}=0.030, p=0.976\right)$, lever (Fig. $3 B)$. An additional control group $(n=8)$ received a Credependent channel rhodopsin (AAV-DIO-ChR2) into vmPFC instead of the DIO-hM3Dq, and CNO pretreatment did not alter cue-induced reinstatement in these animals $t_{(12)}=0.061$, $p=0.952,88 \pm 15$ active lever presses compared with vehicle $=$ $89 \pm 14 ; t_{(12)}=0.036, p=0.972,10 \pm 2$ inactive lever presses compared with vehicle $=10 \pm 4)$. Average lever pressing at the end of self-administration was equivalent between groups (Active lever: $t_{(13)}=0.199, p=0.845$, vehicle $=27 \pm 2, \mathrm{CNO}=26 \pm$
$2, t_{(13)}=0.677, p=0.510$; Inactive lever: vehicle $=0 \pm 0, \mathrm{CNO}=$ $0 \pm 0$ ), as was total cocaine intake over the course of selfadministration $\left(t_{(13)}=0.417, p=0.683\right.$, vehicle $=213 \pm 19$ $\mathrm{mg} / \mathrm{kg}, \mathrm{CNO}=225 \pm 20 \mathrm{mg} / \mathrm{kg}$ ).

As before, cocaine-primed reinstatement was not affected by CNO pretreatment (Active lever: $t_{(14)}=1.631, p=0.125$; Inactive lever: $t_{(14)}=1.708, p=0.110$ ) (Fig. 3B). Histological analysis confirmed that expression of the floxed Gq-DREADD was expressed in the vmPFC-NAshell pathway (Fig. 3A). Three rats were eliminated from the final dataset: one lacking DREADD expression and two with off-target expression. At the end of this experiment, we administered a final dose of CNO (or vehicle) to verify CNO's ability to activate vmPFC-NAshell projection neurons. As expected, $\mathrm{CNO}$ induced Fos expression within vmPFC (Welch's corrected $t_{(8.63)}=2.024, p=0.038$ ) (Fig. $3 C$ ). Thus, chemogenetic vmPFC activation reduces cue-induced reinstatement of cocaine seeking via neurons that project to the NAshell.

As the effects of vmPFC-NAshell activation with the GqDREADD appeared relatively more efficacious compared with the global activation of vmPFC outputs with the non-Credependent DREADD, we asked whether activation of NAshellprojecting vmPFC neurons would reduce cocaine seeking after abstinence. Thus, we repeated this experiment, replacing extinction with home cage abstinence $(n=16)$. Chemogenetic activation of NAshell-projecting vmPFC neurons did not reduce cocaine seeking under these conditions (Active lever: $t_{(12)}=$ 0.195, $p=0.849$; Inactive lever: $t_{(12)}=1.051, p=0.314$ ) (Fig. 4A). As with previous cohorts, expression of the GqDREADD was primarily localized to vmPFC (Fig. $4 B$ ). Two rats were eliminated: one for lack of DREADD expression and an- 
A

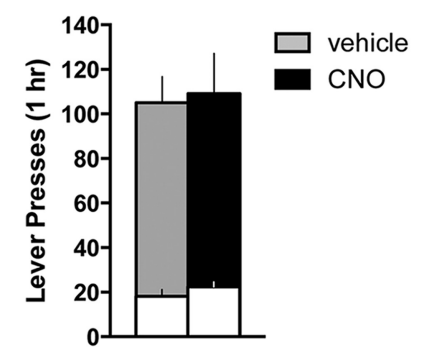

B

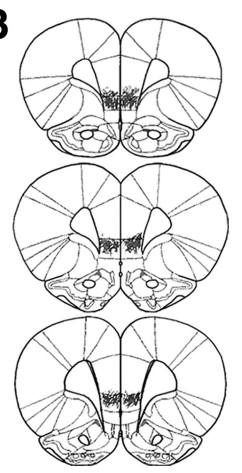

Figure 4. Activation of the vmPFC projection to the NAshell using a retro-DREADD approach does not alter cocaine seeking in the presence of cocaine cues after abstinence. $\boldsymbol{A}$, Neither active (shaded bars) nor inactive (white bars) lever presses differed for CNO versus vehicle-treated animals during the cocaine-seeking test $(p>0.3)$. $\boldsymbol{B}$, Histological verification of the extent of DREADD expression indicated robust and restricted expression in vmPFC.

other for expression in dmPFC. Average lever pressing at the end of self-administration was equivalent between groups (Active lever: $t_{(12)}=0.471, p=0.646$, vehicle $=49 \pm 9, \mathrm{CNO}=57 \pm 12$; Inactive lever: $t_{(12)}=0.524, p=0.610$, vehicle $=1 \pm 0, \mathrm{CNO}=$ $0 \pm 0$ ), as was total cocaine intake during self-administration $\left(t_{(12)}=0.410, p=0.690\right.$, vehicle $=337 \pm 31 \mathrm{mg} / \mathrm{kg}, \mathrm{CNO}=$ $354 \pm 22 \mathrm{mg} / \mathrm{kg})$. In sum, the effects of vmPFC-NAshell activation also depend on extinction training and its associated neuroplasticity.

\section{Discussion}

The present findings support the feasibility of DREADD-based therapy for the treatment of cocaine addiction. Chemogenetic activation of the vmPFC using the Gq-DREADD effectively reduced reinstatement of cocaine seeking triggered by cocaine-associated cues. This effect was only present when prior extinction training was conducted, indicating that extinction-induced plasticity is required for vmPFC activation to reduce cocaine seeking. Restricting the GqDREADD to NAshell-projecting vmPFC neurons was sufficient to recapitulate the reduction in relapse. These data underscore the importance of the vmPFC-NAshell circuit for extinction-induced behavioral inhibition, particularly in the presence of cocaineassociated cues that trigger relapse.

There are many factors that may explain the apparent inability of vmPFC chemogenetic activation to reduce cocaine seeking after abstinence. The neural circuitry regulating cocaine seeking after abstinence may not require the prefrontal cortex; rather, the dorsolateral caudate-putamen appears to be a critical regulator of this form of relapse (Fuchs et al., 2006). Indeed, the prefrontal cortex may be recruited to the neural circuitry regulating reinstatement only after extinction, to resolve the conflict created by these opposing memories "to seek" or "not to seek," depending on current conditions (Quirk et al., 2006; Sharpe and Killcross, 2015). Cocaine craving has been proposed to "incubate" over the course of protracted withdrawal periods like those used in the present study (Tran-Nguyen et al., 1998; Grimm et al., 2001); and although we made no statistical comparisons between our abstinent versus extinction cohorts, cocaine seeking after abstinence was consistently higher than that after extinction $(\sim 15-45$ more active lever presses/h). Thus, extinction-induced plasticity may oppose some of the neuroadaptations driving incubation. However, our data indicate that vmPFC activation, even when restricted to NAshell-projecting neurons, relies on additional extinction-induced plasticity to reduce cocaine seeking, and the

unmasking of silent synapses in the NAshell during protracted abstinence may be permissive to such extinction-related neuroadaptations (Ma et al., 2014).

Interestingly, the effects of vmPFC activation did not extend to relapse triggered by exposure to cocaine. This may result from a cocaine-induced increase in dopamine tone in the NAshell, which has been shown to override the effect of vmPFC activation (LaLumiere et al., 2012). This increase in dopamine would be expected to shift accumbens output from a dopamine D2 to D1 receptor-mediated state (Luo et al., 2011), consistent with reports that D2 signaling reduces, whereas D1 promotes, cocaine seeking (Lobo et al., 2010; Ortinski et al., 2015). Although speculative, this hypothesis predicts that the extinction-like effects of vmPFC activation could be mediated through projections to D2expressing NAshell medium spiny neurons (Berendse et al., 1992). Future studies in D2 knock-out or transgenic lines will be necessary to address this hypothetical anatomy.

The basolateral amygdala (BLA) is a critical component of the neural circuitry mediating cue-induced reinstatement (McLaughlin and See, 2003), but not cocaine-primed reinstatement (McFarland and Kalivas, 2001). One alternative explanation for the selective effect on cue-induced reinstatement may involve a relay through the BLA. Approximately $7 \%$ of vmPFC projections to the NAshell collateralize to the BLA (Pinto and Sesack, 2000). The retro-DREADD approach used to target the vmPFC-NAshell pathway does not rule out the potential involvement of collateralized targets. Activation of these neurons with the Gq-DREADD would be expected to result in glutamate release in the BLA and activation of BLA output, which theoretically promotes cue-induced reinstatement of cocaine seeking. However, glutamatergic mechanisms within the BLA have also been implicated in extinction of cocaine-associated cues (Feltenstein and See, 2007). Thus, it is possible that coordinate activation of vmPFC inputs to the BLA may contribute to the extinctionlike reductions in cocaine seeking observed with chemogenetic activation of the vmPFC-NAshell pathway here.

Another important consideration is the role of contextual conditioned cues on extinction and relapse in the present study. The hippocampus sends glutamatergic projections to both the vmPFC and the medial NAshell (Berendse et al., 1992; Brog et al., 1993; Hoover and Vertes, 2007), and these projections likely convey important information about the context in which behavior occurs (Bouton, 2002, 2006). Hippocampal input to the vmPFC is known to be important for extinction memory consolidation and retrieval (Kalisch et al., 2006; Peters et al., 2010), which may reflect the importance of the conditioned context in gating responses to discrete conditioned cues (O'Donnell and Grace, 1995; Sotres-Bayon et al., 2012). In the present study, contextual cues were extinguished before testing the ability of discrete cocaine cues to trigger reinstatement. Thus, it is possible that vmPFC activation promotes retrieval of a context extinction memory that opposes cocaine seeking triggered by the unextinguished, discrete cocaine cues. Given that prefrontal and hippocampal inputs converge onto the same accumbens neurons (French and Totterdell, 2002), coordinated plasticity in these systems may be required for chemogenetic vmPFC activation to alter accumbens output.

It is important to note that, in the present study, we eliminated animals where DREADD expression was absent, as well as those where expression was not restricted to vmPFC. However, we did not eliminate animals based on terminal fiber expression at the level of the nucleus accumbens (in the retro-DREADD cohorts). DREADD expression was evident in fibers within the NAshell, 
but also frequently in more medial regions, such as the horizontal limb of the diagonal band. Indeed, the vmPFC projects to this area (Vertes, 2004), which is highly interconnected with the hippocampus (Swanson, 1977). Thus, this pathway may also integrate contextual information from the hippocampus with behavioral action and contribute to the extinction-promoting effects of CNO observed in the present study. Unlike the NAshell, however, neurons in the diagonal band project back to the prefrontal cortex (Bloem et al., 2014). It will be imperative to determine whether this feedback loop is important for extinction, or whether projections from the NAshell to the ventral pallidum, hypothalamus, or ventral tegmental area are key outputs (Groenewegen et al., 1999; Otake and Nakamura, 2000; Marchant et al., 2010).

In this study, we were able to promote extinction-like reductions in cocaine seeking in the presence of cocaine cues by chemogenetically activating a discrete projection from vmPFC to NAshell. Approximately $23 \%$ of layer 5 neurons in vmPFC project to the ventral striatum (Gabbott et al., 2005); and although we did not quantify this in the present study, the expression levels observed in vmPFC after CAV-Cre injections in the NAshell are consistent with this estimate. However, functional neuronal ensembles responsible for encoding specific memories are estimated to be on the order of $3 \%-6 \%$ of the total neuronal population, which is a much more restricted population than the one targeted with our retro-DREADD approach. It will be important to determine the relevant efferent targets of extinction memory ensembles in vmPFC, for example, using a Tet-tagged DREADD approach (Garner et al., 2012; Zhang et al., 2015). Given that these ensembles appear to be separate from those encoding reward (Warren et al., 2016), diverse functional ensembles within vmPFC may explain the apparent lack of a vmPFC-mediated inhibition of heroin-seeking animals (Bossert et al., 2011, 2012; Peters et al., 2013).

Future studies should also address the ability of chemogenetic vmPFC activation to reduce cocaine seeking in models that use prolonged access to cocaine and models that focus on individual differences in addiction vulnerability (Ahmed and Koob, 1998; Deroche-Gamonet et al., 2004). Nonetheless, the present data denote the first use of DREADD-based therapies to exploit known extinction circuits to reduce cocaine relapse. Activation of the Gq-DREADD within the vmPFC-NAshell pathway promoted extinction-like reductions in relapse in the face of reminder cues. Selective targeting of extinction neural circuits in this manner may provide effective treatment with reduced side effects through other systems.

\section{References}

Ahmed SH, Koob GF (1998) Transition from moderate to excessive drug intake: change in hedonic set point. Science 282:298-300. CrossRef Medline

Alexander GM, Rogan SC, Abbas AI, Armbruster BN, Pei Y, Allen JA, Nonneman RJ, Hartmann J, Moy SS, Nicolelis MA, McNamara JO, Roth BL (2009) Remote control of neuronal activity in transgenic mice expressing evolved G protein-coupled receptors. Neuron 63:27-39. CrossRef Medline

Armbruster BN, Li X, Pausch MH, Herlitze S, Roth BL (2007) Evolving the lock to fit the key to create a family of $\mathrm{G}$ protein-coupled receptors potently activated by an inert ligand. Proc Natl Acad Sci U S A 104:51635168. CrossRef Medline

Berendse HW, Galis-de Graaf Y, Groenewegen HJ (1992) Topographical organization and relationship with ventral striatal compartments of prefrontal corticostriatal projections in the rat. J Comp Neurol 316:314-347. CrossRef Medline

Bloem B, Schoppink L, Rotaru DC, Faiz A, Hendriks P, Mansvelder HD, van de Berg WD, Wouterlood FG (2014) Topographic mapping between basal forebrain cholinergic neurons and the medial prefrontal cortex in mice. J Neurosci 34:16234-16246. CrossRef Medline

Boender AJ, de Jong JW, Boekhoudt L, Luijendijk MC, van der Plasse G, Adan RA (2014) Combined use of the canine adenovirus-2 and DREADDtechnology to activate specific neural pathways in vivo. PLoS One 9:e95392. CrossRef Medline

Bossert JM, Stern AL, Theberge FR, Cifani C, Koya E, Hope BT, Shaham Y (2011) Ventral medial prefrontal cortex neuronal ensembles mediate context-induced relapse to heroin. Nat Neurosci 14:420-422. CrossRef Medline

Bossert JM, Stern AL, Theberge FR, Marchant NJ, Wang HL, Morales M, Shaham Y (2012) Role of projections from ventral medial prefrontal cortex to nucleus accumbens shell in context-induced reinstatement of heroin seeking. J Neurosci 32:4982-4991. CrossRef Medline

Bouton ME (2002) Context, ambiguity, and unlearning: sources of relapse after behavioral extinction. Biol Psychiatry 52:976-986. CrossRef Medline

Bouton ME, Westbrook RF, Corcoran KA, Maren S (2006) Contextual and temporal modulation of extinction: behavioral and biological mechanisms. Biol Psychiatry 60:352-360. CrossRef Medline

Brog JS, Salyapongse A, Deutch AY, Zahm DS (1993) The patterns of afferent innervation of the core and shell in the "accumbens" part of the rat ventral striatum: immunohistochemical detection of retrogradely transported fluoro-gold. J Comp Neurol 338:255-278. CrossRef Medline

Burgos-Robles A, Vidal-Gonzalez I, Santini E, Quirk GJ (2007) Consolidation of fear extinction requires NMDA receptor-dependent bursting in the ventromedial prefrontal cortex. Neuron 53:871-880. CrossRef Medline

Capriles N, Rodaros D, Sorge RE, Stewart J (2003) A role for the prefrontal cortex in stress- and cocaine-induced reinstatement of cocaine seeking in rats. Psychopharmacology (Berl) 168:66-74. CrossRef Medline

Chiarlone A, Bellocchio L, Blázquez C, Resel E, Soria-Gómez E, Cannich A, Ferrero JJ, Sagredo O, Benito C, Romero J, Sánchez-Prieto J, Lutz B, Fernández-Ruiz J, Galve-Roperh I, Guzmán M (2014) A restricted population of CB1 cannabinoid receptors with neuroprotective activity. Proc Natl Acad Sci U S A 111:8257-8262. CrossRef Medline

Deroche-Gamonet V, Belin D, Piazza PV (2004) Evidence for addiction-like behavior in the rat. Science 305:1014-1017. CrossRef Medline

Do-Monte FH, Manzano-Nieves G, Quiñones-Laracuente K, Ramos-Medina L, Quirk GJ (2015) Revisiting the role of infralimbic cortex in fear extinction with optogenetics. J Neurosci 35:3607-3615. CrossRef Medline

Dunsmoor JE, Niv Y, Daw N, Phelps EA (2015) Rethinking extinction. Neuron 88:47-63. CrossRef Medline

Feltenstein MW, See RE (2007) NMDA receptor blockade in the basolateral amygdala disrupts consolidation of stimulus-reward memory and extinction learning during reinstatement of cocaine-seeking in an animal model of relapse. Neurobiol Learn Mem 88:435-444. CrossRef Medline

French SJ, Totterdell S (2002) Hippocampal and prefrontal cortical inputs monosynaptically converge with individual projection neurons of the nucleus accumbens. J Comp Neurol 446:151-165. CrossRef Medline

Fuchs RA, Branham RK, See RE (2006) Different neural substrates mediate cocaine seeking after abstinence versus extinction training: a critical role for the dorsolateral caudate-putamen. J Neurosci 26:3584-3588. CrossRef Medline

Gabbott PL, Warner TA, Jays PR, Salway P, Busby SJ (2005) Prefrontal cortex in the rat: projections to subcortical autonomic, motor, and limbic centers. J Comp Neurol 492:145-177. CrossRef Medline

Garner AR, Rowland DC, Hwang SY, Baumgaertel K, Roth BL, Kentros C, Mayford M (2012) Generation of a synthetic memory trace. Science 335: 1513-1516. CrossRef Medline

Grimm JW, Hope BT, Wise RA, Shaham Y (2001) Neuroadaptation: incubation of cocaine craving after withdrawal. Nature 412:141-142. CrossRef Medline

Groenewegen HJ, Wright CI, Beijer AV, Voorn P (1999) Convergence and segregation of ventral striatal inputs and outputs. Ann N Y Acad Sci 877: 49-63. CrossRef Medline

Hoover WB, Vertes RP (2007) Anatomical analysis of afferent projections to the medial prefrontal cortex in the rat. Brain Struct Funct 212:149-179. CrossRef Medline

Kalisch R, Korenfeld E, Stephan KE, Weiskopf N, Seymour B, Dolan RJ (2006) Context-dependent human extinction memory is mediated by a ventromedial prefrontal and hippocampal network. J Neurosci 26:95039511. CrossRef Medline

Kalivas PW (2008) Addiction as a pathology in prefrontal cortical regula- 
tion of corticostriatal habit circuitry. Neurotox Res 14:185-189. CrossRef Medline

Kerstetter KA, Wunsch AM, Nakata KG, Donckels E, Neumaier JF, Ferguson SM (2016) Corticostriatal afferents modulate responsiveness to psychostimulant drugs and drug-associated stimuli. Neuropsychopharmacology 41:1128-1137. CrossRef Medline

Koya E, Uejima JL, Wihbey KA, Bossert JM, Hope BT, Shaham Y (2009) Role of ventral medial prefrontal cortex in incubation of cocaine craving. Neuropharmacology. 56 [Suppl 1]:177-185.

LaLumiere RT, Niehoff KE, Kalivas PW (2010) The infralimbic cortex regulates the consolidation of extinction after cocaine self-administration. Learn Mem 17:168-175. CrossRef Medline

LaLumiere RT, Smith KC, Kalivas PW (2012) Neural circuit competition in cocaine-seeking: roles of the infralimbic cortex and nucleus accumbens shell. Eur J Neurosci 35:614-622. CrossRef Medline

Li H, Penzo MA, Taniguchi H, Kopec CD, Huang ZJ, Li B (2013) Experience-dependent modification of a central amygdala fear circuit. Nat Neurosci 16:332-339. CrossRef Medline

Lobo MK, Covington HE 3rd, Chaudhury D, Friedman AK, Sun H, DamezWerno D, Dietz DM, Zaman S, Koo JW, Kennedy PJ, Mouzon E, Mogri M, Neve RL, Deisseroth K, Han MH, Nestler EJ (2010) Cell type-specific loss of BDNF signaling mimics optogenetic control of cocaine reward. Science 330:385-390. CrossRef Medline

Luo Z, Volkow ND, Heintz N, Pan Y, Du C (2011) Acute cocaine induces fast activation of $\mathrm{D} 1$ receptor and progressive deactivation of $\mathrm{D} 2$ receptor striatal neurons: in vivo optical microprobe $\left[\mathrm{Ca}^{2+}\right]$ i imaging. J Neurosci 31:13180-13190. CrossRef Medline

Ma YY, Lee BR, Wang X, Guo C, Liu L, Cui R, Lan Y, Balcita-Pedicino JJ, Wolf ME, Sesack SR, Shaham Y, Schlüter OM, Huang YH, Dong Y (2014) Bidirectional modulation of incubation of cocaine craving by silent synapse-based remodeling of prefrontal cortex to accumbens projections. Neuron 83:1453-1467. CrossRef Medline

Mahler SV, Vazey EM, Beckley JT, Keistler CR, McGlinchey EM, Kaufling J, Wilson SP, Deisseroth K, Woodward JJ, Aston-Jones G (2014) Designer receptors show role for ventral pallidum input to ventral tegmental area in cocaine seeking. Nat Neurosci 17:577-585. CrossRef Medline

Marchant NJ, Furlong TM, McNally GP (2010) Medial dorsal hypothalamus mediates the inhibition of reward seeking after extinction. J Neurosci 30:14102-14115. CrossRef Medline

Marchant NJ, Whitaker LR, Bossert JM, Harvey BK, Hope BT, Kaganovsky K, Adhikary S, Prisinzano TE, Vardy E, Roth BL, Shaham Y (2016) Behavioral and physiological effects of a novel kappa-opioid receptor-based DREADD in rats. Neuropsychopharmacology 41:402-409. CrossRef Medline

McFarland K, Kalivas PW (2001) The circuitry mediating cocaine-induced reinstatement of drug-seeking behavior. J Neurosci 21:8655-8663. Medline

McLaughlin J, See RE (2003) Selective inactivation of the dorsomedial prefrontal cortex and the basolateral amygdala attenuates conditioned-cued reinstatement of extinguished cocaine-seeking behavior in rats. Psychopharmacology (Berl) 168:57-65. CrossRef Medline

Moorman DE, James MH, McGlinchey EM, Aston-Jones G (2015) Differential roles of medial prefrontal subregions in the regulation of drug seeking. Brain Res 1628:130-146. CrossRef Medline

Nic Dhonnchadha BÁ, Kantak KM (2011) Cognitive enhancers for facilitating drug cue extinction: insights from animal models. Pharmacol Biochem Behav 99:229-244. CrossRef Medline

O’Donnell P, Grace AA (1995) Synaptic interactions among excitatory afferents to nucleus accumbens neurons: hippocampal gating of prefrontal cortical input. J Neurosci 15:3622-3639. Medline

Ortinski PI, Briand LA, Pierce RC, Schmidt HD (2015) Cocaine-seeking is associated with PKC-dependent reduction of excitatory signaling in accumbens shell D2 dopamine receptor-expressing neurons. Neuropharmacology 92:80-89. CrossRef Medline

Otake K, Nakamura Y (2000) Possible pathways through which neurons of the shell of the nucleus accumbens influence the outflow of the core of the nucleus accumbens. Brain Dev 22 [Suppl 1]:S17-S26.

Peters J, LaLumiere RT, Kalivas PW (2008) Infralimbic prefrontal cortex is responsible for inhibiting cocaine seeking in extinguished rats. J Neurosci 28:6046-6053. CrossRef Medline

Peters J, Kalivas PW, Quirk GJ (2009) Extinction circuits for fear and addiction overlap in prefrontal cortex. Learn Mem 16:279-288. CrossRef Medline

Peters J, Dieppa-Perea LM, Melendez LM, Quirk GJ (2010) Induction of fear extinction with hippocampal-infralimbic BDNF. Science 328:12881290. CrossRef Medline

Peters J, Pattij T, De Vries TJ (2013) Targeting cocaine versus heroin memories: divergent roles within ventromedial prefrontal cortex. Trends Pharmacol Sci 34:689-695. CrossRef Medline

Pickens CL, Airavaara M, Theberge F, Fanous S, Hope BT, Shaham Y (2011) Neurobiology of the incubation of drug craving. Trends Neurosci 34:411420. CrossRef Medline

Pinto A, Sesack SR (2000) Limited collateralization of neurons in the rat prefrontal cortex that project to the nucleus accumbens. Neuroscience 97:635-642. CrossRef Medline

Quirk GJ, Garcia R, González-Lima F (2006) Prefrontal mechanisms in extinction of conditioned fear. Biol Psychiatry 60:337-343. CrossRef Medline

Sesack SR, Deutch AY, Roth RH, Bunney BS (1989) Topographical organization of the efferent projections of the medial prefrontal cortex in the rat: an anterograde tract-tracing study with Phaseolus vulgaris leucoagglutinin. J Comp Neurol 290:213-242. CrossRef Medline

Sharpe M, Killcross S (2015) The prelimbic cortex uses contextual cues to modulate responding towards predictive stimuli during fear renewal. Neurobiol Learn Mem 118:20-29. CrossRef Medline

Sinha R (2013) The clinical neurobiology of drug craving. Curr Opin Neurobiol 23:649-654. CrossRef Medline

Sotres-Bayon F, Sierra-Mercado D, Pardilla-Delgado E, Quirk GJ (2012) Gating of fear in prelimbic cortex by hippocampal and amygdala inputs. Neuron 76:804-812. CrossRef Medline

Swanson LW (1977) The anatomical organization of septo-hippocampal projections. Ciba Found Symp 58:25-48. Medline

Tran-Nguyen LT, Fuchs RA, Coffey GP, Baker DA, O’Dell LE, Neisewander JL (1998) Time-dependent changes in cocaine-seeking behavior and extracellular dopamine levels in the amygdala during cocaine withdrawal. Neuropsychopharmacology 19:48-59. CrossRef Medline

Van den Oever MC, Rotaru DC, Heinsbroek JA, Gouwenberg Y, Deisseroth K, Stuber GD, Mansvelder HD, Smit AB (2013) Ventromedial prefrontal cortex pyramidal cells have a temporal dynamic role in recall and extinction of cocaine-associated memory. J Neurosci 33:18225-18233. CrossRef Medline

Vertes RP (2004) Differential projections of the infralimbic and prelimbic cortex in the rat. Synapse 51:32-58. CrossRef Medline

Warren BL, Mendoza MP, Cruz FC, Leao RM, Caprioli D, Rubio FJ, Whitaker LR, McPherson KB, Bossert JM, Shaham Y, Hope BT (2016) Distinct Fos-expressing neuronal ensembles in the ventromedial prefrontal cortex mediate food reward and extinction memories. J Neurosci 36:6691-6703. CrossRef Medline

Weissenborn R, Robbins TW, Everitt BJ (1997) Effects of medial prefrontal or anterior cingulate cortex lesions on responding for cocaine under fixed-ratio and second-order schedules of reinforcement in rats. Psychopharmacology (Berl) 134:242-257. CrossRef Medline

Xue YX, Luo YX, Wu P, Shi HS, Xue LF, Chen C, Zhu WL, Ding ZB, Bao YP, Shi J, Epstein DH, Shaham Y, Lu L (2012) A memory retrievalextinction procedure to prevent drug craving and relapse. Science 336: 241-245. CrossRef Medline

Zhang Z, Ferretti V, Guntan I, Moro A, Steinberg EA, Ye Z, Zecharia AY, Yu X, Vyssotski AL, Brickley SG, Yustos R, Pillidge ZE, Harding EC, Wisden W, Franks NP (2015) Neuronal ensembles sufficient for recovery sleep and the sedative actions of $\alpha 2$ adrenergic agonists. Nat Neurosci 18:553561. CrossRef Medline 